\title{
Paul W. Kruse (1927-2012), In Memoriam
}

\section{Marion Reine, Paul Norton, Ernie Stelzer}

Marion B. Reine, Paul R. Norton, Ernie L. Stelzer, "Paul W. Kruse (1927-2012), In Memoriam," Proc. SPIE 8704, Infrared Technology and Applications XXXIX, 87041F (11 June 2013); doi: 10.1117/12.2020075

Event: SPIE Defense, Security, and Sensing, 2013, Baltimore, Maryland, United States 


\title{
Paul W. Kruse (1927-2012), In Memoriam
}

\author{
Marion B. Reine \\ Consultant, Infrared Detectors \\ Cambridge, Massachusetts \\ Paul R. Norton \\ U.S. Army Night Vision \& Electronic Sensors Directorate \\ Fort Belvoir, Virginia \\ Ernie L. Stelzer \\ Honeywell Research Center (retired) \\ Minnetonka, Minnesota
}

\begin{abstract}
During his distinguished 37-year career as a research physicist at the Honeywell Research Center in Minneapolis, Minnesota, Dr. Paul W. Kruse (1927-2012) played leadership roles in two disruptive infrared detector technologies, the narrow-gap semiconductor alloy $\mathrm{HgCdTe}$ and the silicon CMOS-based microbolometer array, both of which revolutionized the worldwide infrared detector industry. He served on numerous government advisory boards and panels, including the Army Scientific Advisory Panel and the Army Science Board, for which he received the Outstanding Civilian Service Medal. After retiring from Honeywell in 1993, he remained active in the infrared detector field in several roles: as a successful small-business entrepreneur, as an author of two books, and as a SPIE lecturer. His books, papers and lectures have educated new generations of workers in the infrared detector industry. His career, a model for industrial research physicists, has had major and permanent impacts on the worldwide infrared detector industry. This paper is a summary of the career of Paul W. Kruse, as well as a tribute to that career and its lasting legacy.
\end{abstract}

Keywords: Paul Kruse, HgCdTe, photon detector, microbolometer, history of infrared, infrared detector, Honeywell

\section{Beginnings and Education}

Paul Walters Kruse Jr. was born on Nov. 24th, 1927 in Hibbing, Minnesota. He grew up in Virginia, Minnesota, a small mining town in the northeast corner of Minnesota, where his father was superintendent for the Jones and Laughlin Steel Corporation.

Paul was drafted into the Army in 1945, and served at a Field Hospital unit in Taejun, Korea in 1947-48.

After leaving the Army, Paul attended the University of Notre Dame, where he earned his B.S. (1951), M.S. (1952) and Ph.D. (1954) degrees, all in physics. His $\mathrm{Ph} . \mathrm{D}$. thesis title is "A study of the kinetics of strontium oxide on molybdenum as a function of temperature, made by means of the field emission microscope."

\section{First Job}

In 1954, Paul joined the Capehart Farnsworth Electronics Company (later known as the ITT Industrial Laboratories) in Fort Wayne, Indiana as a solid state

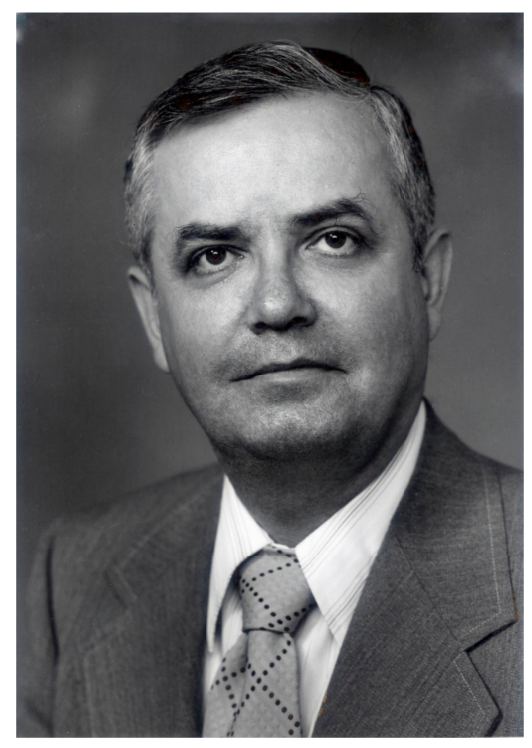

\footnotetext{
Infrared Technology and Applications XXXIX, edited by Bjørn F. Andresen, Gabor F. Fulop,

Charles M. Hanson, Paul R. Norton, Proc. of SPIE Vol. 8704, 87041F · (c) 2013 SPIE

CCC code: $0277-786 X / 13 / \$ 18 \cdot$ doi: $10.1117 / 12.2020075$
} 
physicist, where he studied CdSe and PbTe photoconductors. This first job is where Paul was introduced to solid state physics and infrared technology, which would become the cornerstones of his career.
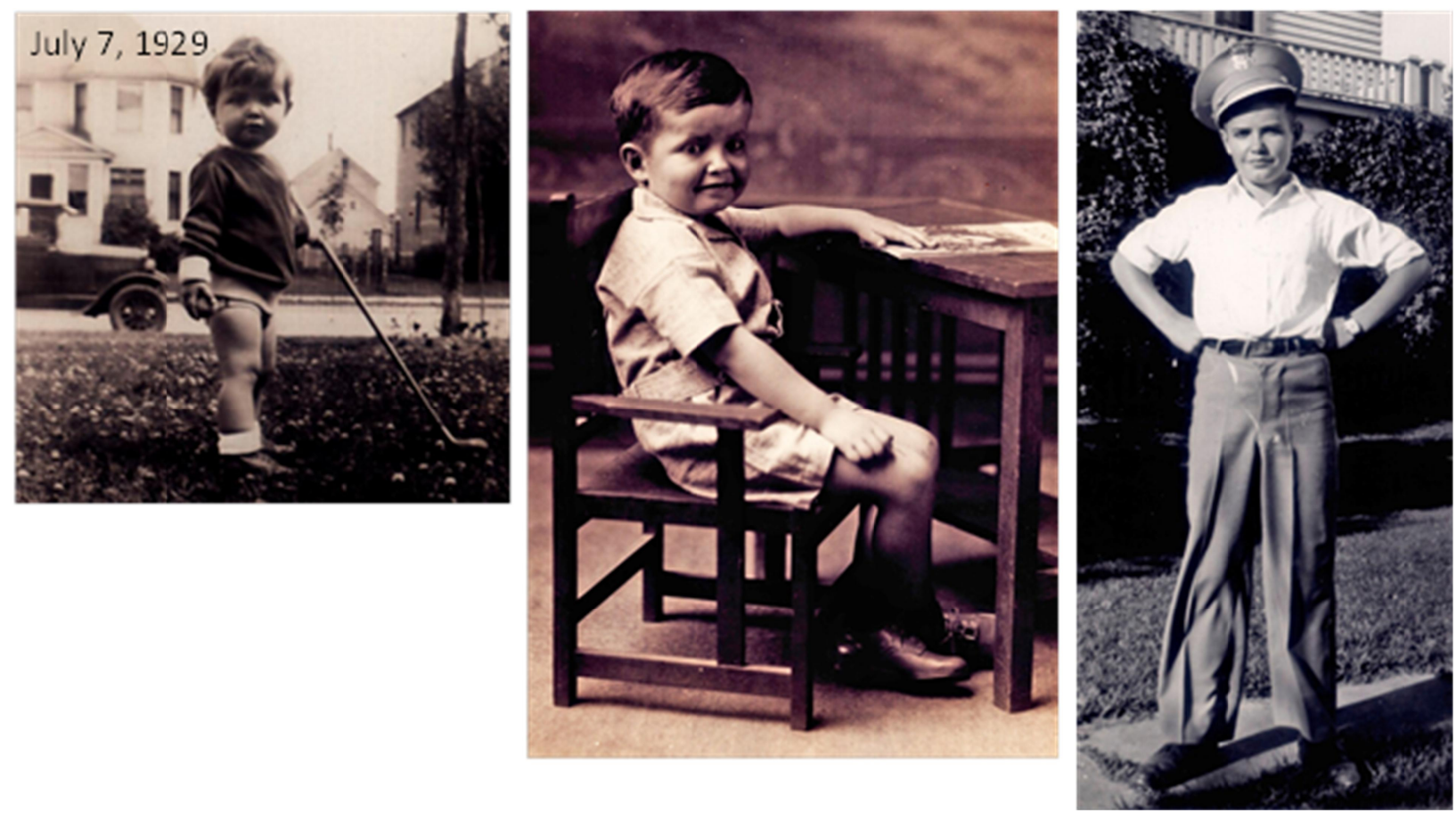

Figure 1. Early photos of Paul Kruse, as a two-year-old novice golfer in 1929 (left), as an incipient scholar (middle) and in his school band uniform (right).
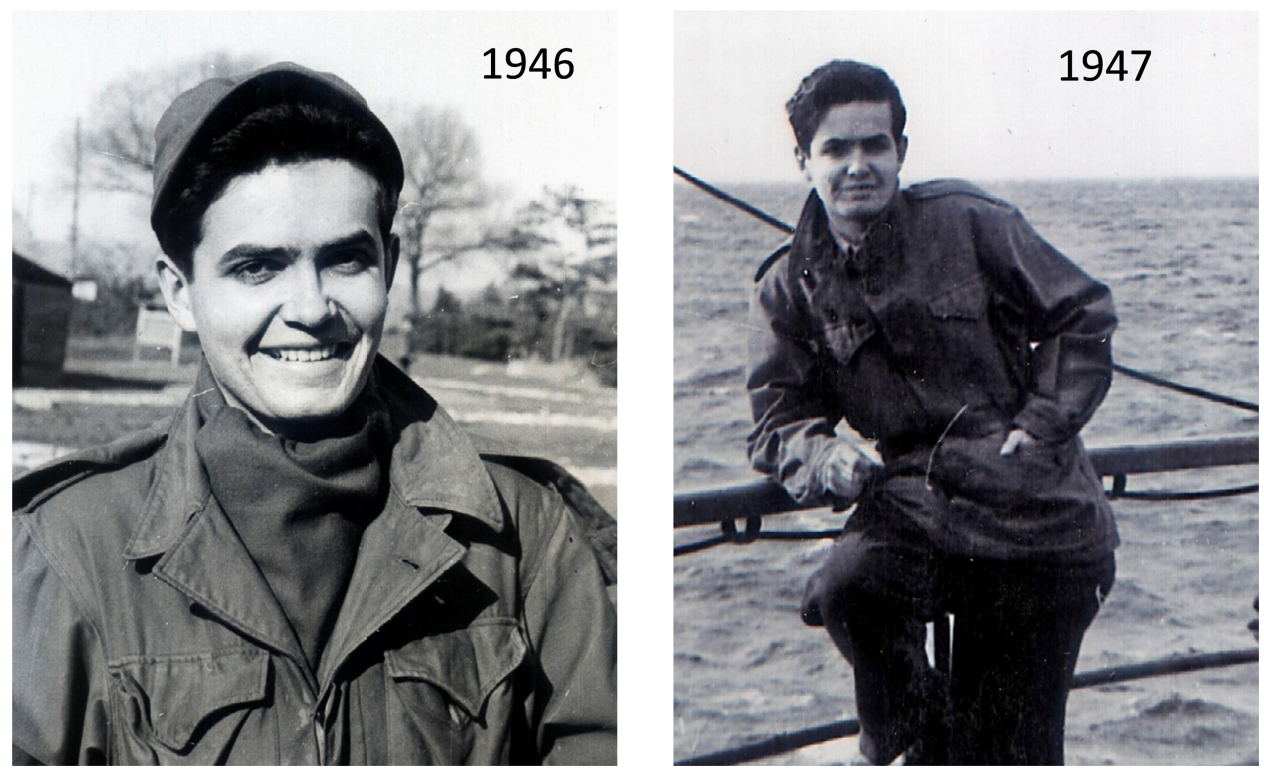

Figure 2. Paul Kruse served in the Army in 1945-48. He was stationed at a Field Hospital unit in Taejun, Korea in 1947-48. 


\section{Thirty-Seven Year Career at the Honeywell Research Center}

In 1956, Paul joined the Honeywell Corporate Research Center in Hopkins, Minnesota as a solid state physicist, where he spent the next 37 years advancing the science and technology of infrared detectors and other solid state devices, as well as advising the Army and other government agencies on matters of infrared science and technology.

In his 37 year career with Honeywell, Paul made in-depth contributions to research in a large number of topics dealing with infrared detector science and technology. The major topics he worked on are listed in roughly chronological order in Table 1. This list includes InSb photoconductive and photoelectromagnetic infrared detectors, Ge-GaAs heterojunctions, and the ternary wide-gap alloy $\mathrm{ZnSiP}$ for photoconductive visible detection (flame detection was an ongoing important research area for Honeywell because of its products in industrial control systems). Paul studied nonlinear optical effects in $\mathrm{HgCdTe}$, including the spin-flip Raman laser, four-photon mixing, optical phase conjugation and optical bistability. He also studied optical bistability in GaAs/AlGaAs superlattices.

But Paul's career will probably be most remembered for his timely technical leadership in two disruptive infrared detector technologies: the semiconductor alloy $\mathrm{HgCdTe}$ and uncooled microbolometer two-dimensional arrays.

- InSb photoelectromagnetic IR detector, marketed by Honeywell

- CdS and CdSe for photosensitive potentiometer

- IR modulator based on free carrier absorption in Ge for IR communications

- IR methods for cancer detection

- HgCdTe IR materials and detectors

- Ge-GaAs heterojunctions

- ZnSiP photoconductor for visible detection (flame detection)

- Application of near-mm wave technology to imaging systems

- Non-linear optical effects in $\mathrm{HgCdTe}$, leading to the first spin-flip HgCdTe Raman laser

- Optical bistability in GaAs-AlGaAs superlattices

- Uncooled imaging based on arrays of microbolometers \& lead titanate thin film pyroelectric detectors

- High transition temperature superconductors for IR detection \& imaging

- Imaging spectroradiometer for potential use on a Mars rover

Table 1. Research topics that Paul Kruse worked on during his 37 year career at the Honeywell Corporate Research Center, listed in roughly chronological order.

Around 1960-1961, Paul and two of his Honeywell colleagues, Don McGlauchlin and Rich McQuistan, completed the manuscript for a book that became a seminal foundational resource for the infrared detector industry. This classic book, Elements of Infrared Technology, was published in 1962 by Wiley. Coincidentally, another classic foundational book, Semiconductor Statistics by John Blakemore, ${ }^{1}$ who was working at that time at the Honeywell Research Center, was published by Pergamon Press also in that year. Paul recalled his informative discussions with Blakemore on the emerging theory of recombination mechanisms in narrow-gap semiconductors. 


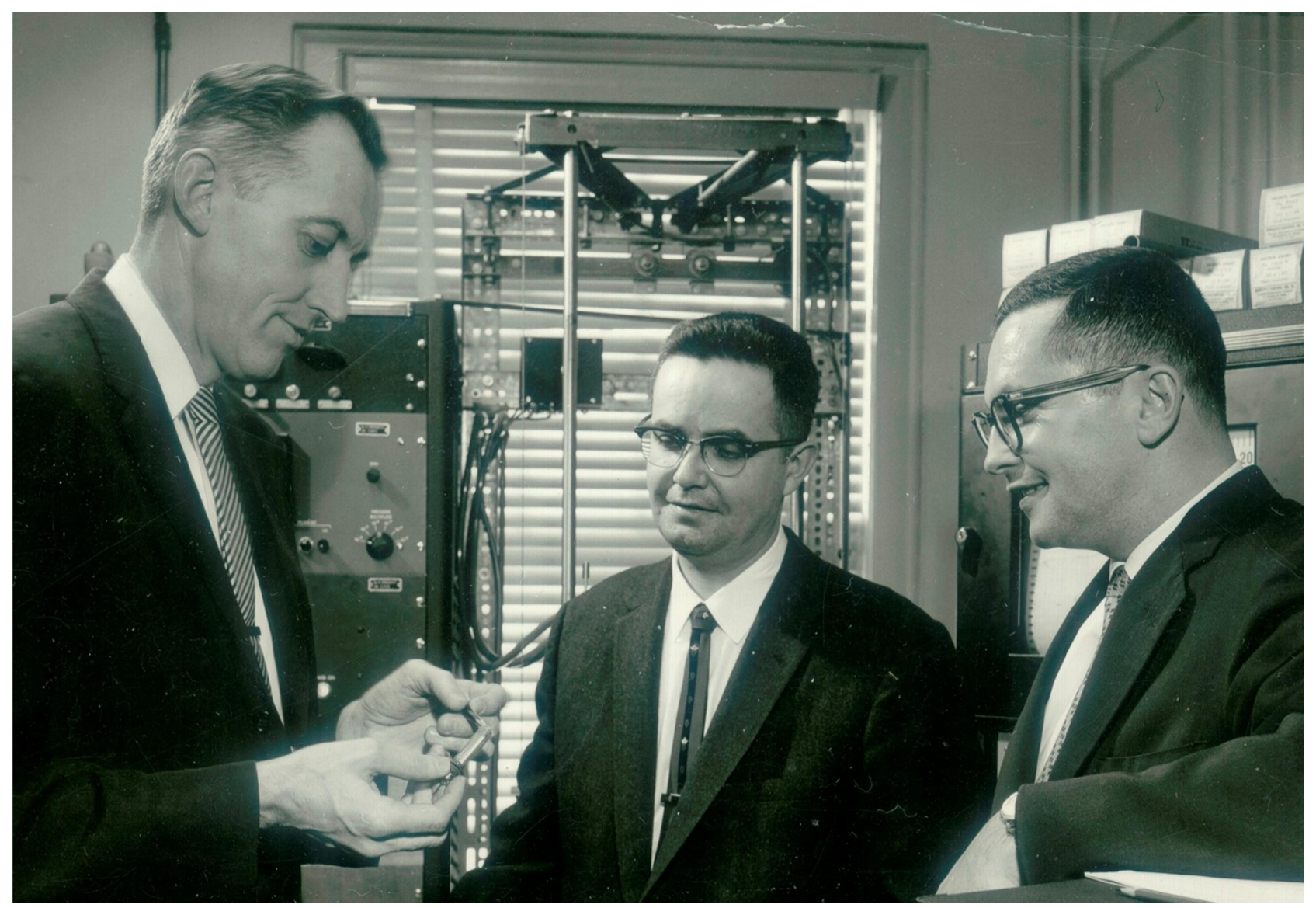

Figure 3. Laurence D. (Don) McGlauchlin Paul Kruse and Richmond (Rich) B. McQuistan, authors of Elements of infrared technology: Generation, transmission and detection (New York, Wiley, 1962). This photo was taken in a laboratory at the Honeywell Corporate Research Center, Hopkins, Minnesota, around 1962. Don is holding a bottom-looking glass dewar used for packaging and testing infrared detectors.

In the early 1980's, Paul championed successful efforts to institute the Fellows program throughout the Honeywell Corporation. This dual-ladder program allowed scientists and engineers to advance their careers along a path that was parallel to the traditional management track, with equivalent pay increases and promotions.

Paul was always application-oriented. His projects were always directed toward a new product or new capability. He was certainly capable of doing physics for physics sake, but his passion and enjoyment derived from the new applications that his physics made possible.

Paul joined the Honeywell Research Center toward the end of the "Golden Age" of the corporate research center.

Corporate funding for research became less bountiful than it had been in the years following the glamorous adventures at Bell Laboratories in the invention of the transistor. Paul was quite successful in originating and writing proposals, and much of his work at Honeywell had external contract support.

Paul's rapidly advancing career with a growing list of technical and research accomplishments, together with his personal leadership skills, caused him to became a role model for a generation of Honeywell applied physicists and engineers. Paul somehow was able to adroitly balance physics, devices, Honeywell, the Government....and his growing family.

Paul retired from Honeywell in 1993 as Chief Research Fellow. 


\section{Paul Kruse's Pioneering Leadership in HgCdTe}

The early history of HgCdTe in the late 1950's and early 1960's is the subject of several recent invited papers that were presented at the special session "HgCdTe: 50 Year Anniversary Session," which was part of the SPIE symposium in April 13-17, 2009, at Orlando, Florida. ${ }^{2-5}$ There is a chapter by Ernest Putley in the 1999 book Cold War, Hot Science: Applied Research in Britain's Defence Laboratories 1945-1990. Some of Paul Kruse's recollections are in a letter he wrote in 1999.

The first publication of the synthesis of the narrow-gap semiconductor alloy mercury-cadmium telluride (HgCdTe or $\mathrm{Hg}_{1-\mathrm{x}} \mathrm{Cd}_{\mathrm{x}} \mathrm{Te}$ ) was a 1959 paper from the group at the Royal Radar Establishment in Malvern, England. ${ }^{7}$ This seminal paper reported both photoconductive and photovoltaic response at wavelengths extending out to $12 \mu \mathrm{m}$, and made the understated observation that this material showed promise for intrinsic infrared detectors. There is also a patent from this group filed in 1957. ${ }^{89}$ However, as Tom Elliott (Charles Thomas Elliott, FRS, CBE) recounts in his paper, ${ }^{3}$ in spite of the promising initial $\mathrm{HgCdTe}$ results and their implications for thermal imaging, the British government shut down the $\mathrm{HgCdTe}$ effort at RRE by April 1958 because solid state physics RRE resources were needed for work on InSb to replace $\mathrm{PbS}$ in the more urgent application of infrared guidance and homing for missiles.

At the same time, Paul Kruse was working on a Honeywell-funded program to realize a new detector material for the 8$14 \mu \mathrm{m}$ thermal imaging waveband that would allow operation at $77 \mathrm{~K}$. Through discussions with his Honeywell colleague John Blakemore and through the research he was concurrently doing on his book Elements of Infrared Technology, Paul knew the key characteristics that such a material must have, namely a direct band gap for high absorption and long excess carrier lifetimes. In a competitive procurement in which there were 35 proposals, Paul wrote the successful proposal to the Air Force Avionics Laboratory at Wright-Patterson Air Force Base, Dayton, Ohio for development of a 8-14 $\mu \mathrm{m}$ photon detector operating at $77 \mathrm{~K} .{ }^{10}$

Paul and the Honeywell team devised a "modified" Bridgman crystal growth technique for HgCdTe. They soon reported in 1962 key characteristics of the $\mathrm{HgCdTe}$ alloy as well as both photoconductive and photovoltaic detection in rudimentary $\mathrm{HgCdTe}$ devices. ${ }^{11,12}$ In 1964 they succeeded in demonstrating the first high-quality $\left(\mathrm{D}^{*}{ }_{\mathrm{BB}} \sim 2 \mathrm{e} 9 \mathrm{~cm}-\right.$ $\left.\mathrm{Hz}^{1 / 2} / \mathrm{W}\right) \mathrm{HgCdTe}$ photoconductive detectors. Subsequently, Paul's colleagues, Joe Schmit and Don Long made key contributions to the successful development of $\mathrm{HgCdTe}$ in the areas of improved materials growth processes and lifetime analysis respectively. A letter written by Paul in 1999, reproduced in Appendix B, recounts the details of the early Honeywell success with $\mathrm{HgCdTe}$.

The success of Paul Kruse's Honeywell team did not escape the notice of the British or of other US companies. Ernest Putley ${ }^{6}$ states on page 201 of his historical review chapter: “...Minneapolis-Honeywell made the startling claim that they had succeeded in making CMT detectors with adequate performance at the relatively high temperature of $77 \mathrm{~K} . . . "$ On the same page he writes: "Because they had persisted with research on CMT, Minneapolis-Honeywell were now able to reveal that they had succeeded in manufacturing liquid-nitrogen-cooled 8-13 $\mu \mathrm{m}$ detectors." After seeing the successful Honeywell data on $\mathrm{HgCdTe}$, the British effort resumed their HgCdTe effort at RRE around 1966. Santa Barbara Research Center, Goleta, California and Texas Instruments, Dallas, Texas both initiated HgCdTe programs after learning of the Honeywell success. In the years following this initial success, work on $\mathrm{HgCdTe}$ materials and devices intensified within Honeywell, both at the Corporate Research Center in Minneapolis, Minnesota and at the Radiation Center in Lexington, Massachusetts.

It is important to recognize the various ingredients that were all essential to the Honeywell success in $\mathrm{HgCdTe}$. Internal funds, well equipped research laboratory facilities, world-class research colleagues such as John Blakemore and Don Long, adequate government support with a knowledgeable contract technical monitor, a vibrant research environment that encouraged the concurrent writing of a book, and urgent company applications (recall that Paul was an applicationoriented physicist) at the Honeywell Radiation Center in Lexington, Massachusetts, where several imaging instruments were ready and waiting to use this new $\mathrm{HgCdTe}$ detector at $77 \mathrm{~K}$ for 8-14 $\mu \mathrm{m}$ applications .

Today $\mathrm{HgCdTe}$ is well established as the material of choice as the most widely applicable highest-performance, highestoperating-temperature infrared detector material for a multitude of DoD, NASA and industrial applications, including 
ground-based, airborne and spaceborne instruments that provide thermal imaging, remote sensing of planetary resources and the environment, missile guidance, threat warning, and threat awareness for biological and chemical agents.

Paul was the lead author on the book "Basic Properties of $\mathrm{Hg}_{1-\mathrm{x}} \mathrm{Cd} \mathrm{d}_{\mathrm{x}} \mathrm{Te}$," an internal Honeywell document compiled by the research staff at the Honeywell Corporate Research Center, whose first edition was dated May 1970. This invaluable document kept the early parallel $\mathrm{HgCdTe}$ efforts at the Research Center in Minneapolis and the Radiation Center in Lexington, Massachusetts "on the same page" with regard to the known fundamental semiconductor material and device properties of $\mathrm{Hg}_{1-\mathrm{x}} \mathrm{Cd}_{\mathrm{x}} \mathrm{Te}$ and its performance as a versatile infrared photon detector. This document, which had three editions, was known affectionately as the "Gold Book" because of its front cover. Along with Elements of Infrared Technology, it was on the desk of everyone who worked on $\mathrm{HgCdTe}$ in Honeywell.

\section{Paul Kruse's Leadership in Uncooled Microbolometer Array Technology}

The second of Paul's two revolutionary developments was the silicon-based microbolometer two-dimensional array. The Honeywell Solid State Electronics Division, Honeywell's in-house silicon foundry, had developed silicon microbridge devices originally for gas flow sensors. In the early 1980's, Paul recognized that the high thermal isolation of the microbridge architecture was exactly what was needed for a high-performance uncooled bolometer infrared detector. The early development of the uncooled microbridge infrared detector is described in the review chapter by Paul's Honeywell colleague and collaborator Andrew Wood. This quote from Andrew's chapter ${ }^{13}$ (page 46) describes the role that Paul played in initiating the uncooled microbridge array technology in Honeywell:

"Kruse (1982) showed by calculation that Si micromachined microbolometers could have a performance approaching the ideal performance for a room temperature IR sensor, and proposed their construction as twodimensional staring focal planes for low-cost uncooled IR imaging."

Paul and his Honeywell colleagues Andrew Wood, Bob Higashi, Bob Johnson, C. J. Han and others pioneered the integration of silicon microbridge bolometer detectors with CMOS integrated circuits to develop the first uncooled infrared Focal Plane Arrays (FPAs). Uncooled microbolometer FPA technology advanced rapidly, and today microbolometer FPAs are in worldwide production as the premier technology for low-cost thermal imaging sensors for a wide variety of both commercial and military applications.

\section{Advisor to the Government}

Throughout his Honeywell career, Paul served on numerous advisory boards and studies for the government. His advisory role was fully supported by Honeywell. He was a long-standing member of the Army Scientific Advisory Panel (1965-1977) and the Army Science Board (1978-1982, 1985-1990), for which he received the Outstanding Civilian Service Medal from the Department of the Army in 1983. In 1968-1972, he served on several panels for the President's Science Advisory Committee. He served on several committees for the National Academy of Sciences. A full listing of Paul's service as a government advisor is in Appendix A.

\section{After Retirement from Honeywell}

Paul retired from Honeywell at age 65 in 1993. Afterward he remained active in the infrared detector field in several roles: as a successful small-business entrepreneur, as an author of two books, and as a SPIE lecturer.

In 1994, Paul and seven other Honeywell retirees founded a small company, Infrared Solutions, Inc. Paul spent one-third of his time as Chief Scientist from 1994 to mid-1998. One of their first successful products used an uncooled linear thermoelectric array, designed by Paul, in a radiometer that identified incipient failure of railcar wheels. The scanning was provided by the railcar itself as is rolled past the vertical linear array.

Infrared Solutions, Inc. grew rapidly and soon became a recognized innovator in the application of infrared technology for commercial and industrial use. Sales in 2001 were $\$ 7$ M. The company designs, manufactures and sells a broad range of thermal imaging products for applications across a number of channels including predictive and preventative maintenance. The company's products include rugged, easy-to-use, portable thermographic infrared cameras. In 2005, 
Infrared Solutions, Inc. was bought by Fluke Electronics Corporation, an electronics manufacturer based in Everett, Washington.

Paul conceived and co-edited what has become an important review book in uncooled array technology, entitled Uncooled Infrared Imaging Arrays and Systems, published as Volume 47 of the Semiconductor and Semimetals series, (Academic Press, 1997). Paul co-edited this volume with David Skatrud of the Army Research Office, and wrote two review chapters for this volume.

During the years following his retirement from Honeywell, Paul was a frequent lecturer for SPIE on uncooled infrared array technology and its applications. He taught a well-attended course at SPIE conferences and conducted day-long onsite SPIE "short-course" lectures. His third book, Uncooled Thermal Imaging Arrays, Systems, and Applications, published by SPIE Press in 2001, is an outgrowth of his SPIE course and lecture notes.

\section{Devoted to his Family}

Paul was devoted to his family. He and Marge were married on January 23, 1954, one semester prior to Paul receiving his Ph.D. at Notre Dame. Of their nine children, all but one were educated at Notre Dame. At last count, Paul and Marge have nineteen grandchildren, one of which is at Notre Dame, Class of 2016.

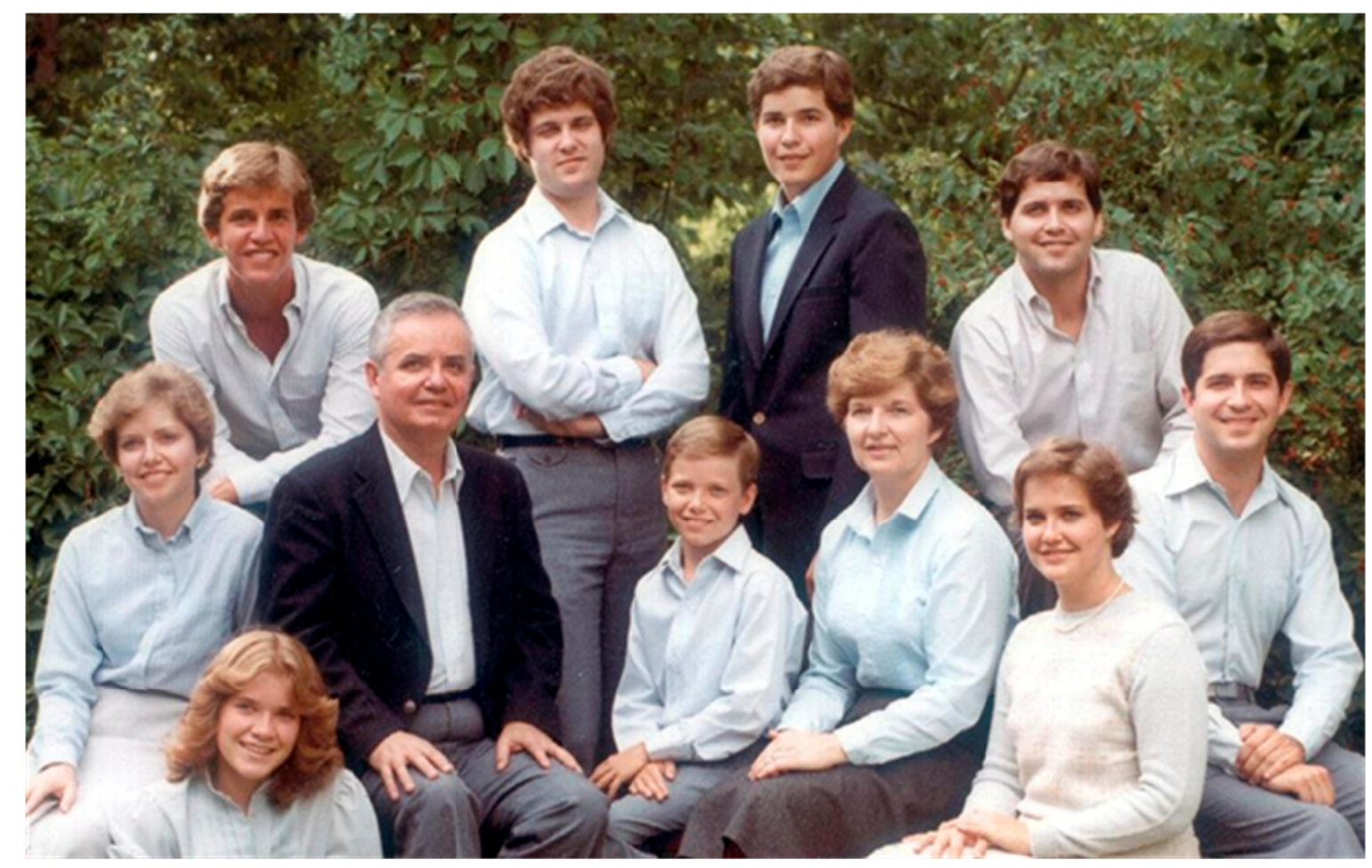

Figure 4. Paul, Marge and their nine children in 1982. 


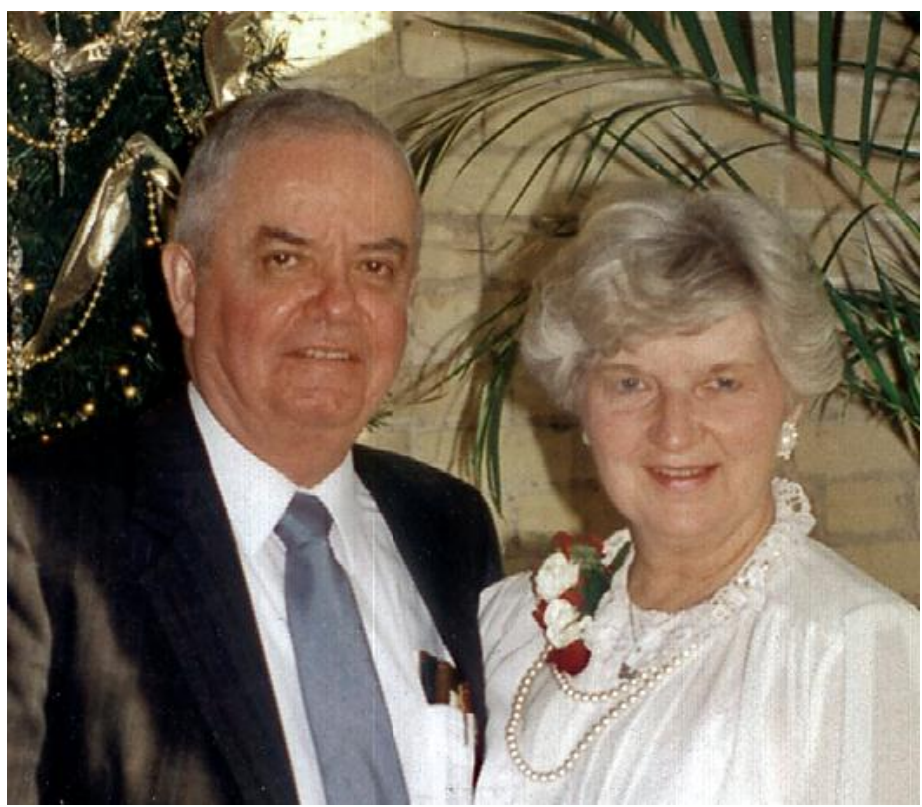

Figure 5. Paul and Marge Kruse on their $40^{\text {th }}$ wedding anniversary on January 23, 1994.

\section{The Quintessential Industrial Research Physicist}

The hallmark of Paul's industrial research career was a passion not only for the basic science of solid state detector materials, but also for the application of this science to useful devices. He was also passionate about his family, his country, and Notre Dame. He was a master of both the spoken and the written word. His books, papers and SPIE courses have educated new generations of infrared detector technologists.

Paul was often the calming voice of reason amidst sometimes contentious meetings on how to realize high-performance $\mathrm{HgCdTe}$ devices with uncertain and incomplete knowledge of the basic underlying science about the material and fabrication methods. Paul's memorable approach was to go to the board or easel and write down...in complete sentences...the issues and what was and was not known.

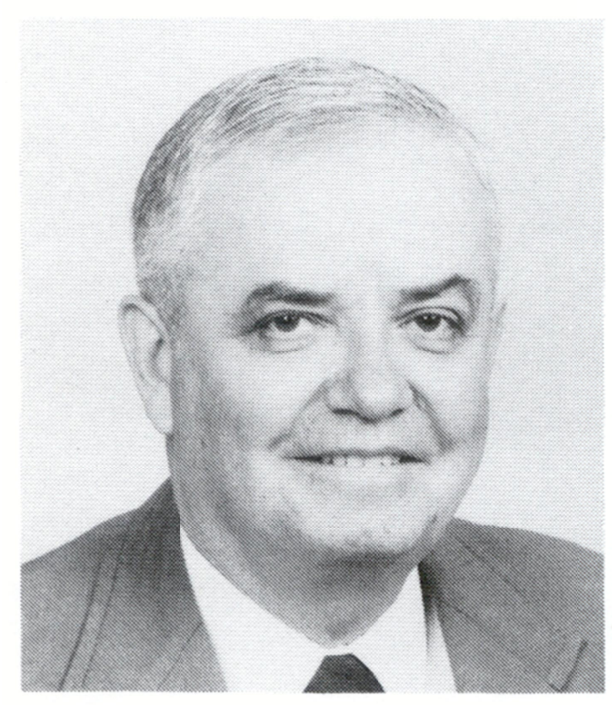

Paul played leadership roles in two disruptive infrared detector technologies, $\mathrm{HgCdTe}$ and the uncooled microbolometer. His career, a model for industrial research physicists, has had major and lasting impacts on the worldwide infrared detector industry.

\section{Acknowledgements}

Marge Kruse, Paul's wife, furnished many photos of Paul as well as recollections and biographical material about Paul's life and career. 


\section{Appendix A}

\section{Books, Chapters, Publications and Presentations, Patents, Honors, Government Panels and Advisory Committees, and Professional Society Activities}

\section{Books}

Paul W. Kruse, Laurence D. McGlauchlin and Richmond B. McQuistan, Elements of infrared technology: Generation, transmission and detection (New York, Wiley, 1962).

P. W. Kruse, D. Long, J. L. Schmit, M. W. Scott, C. J. Speerschneider and E. L. Stelzer, "Basic Properties of $\mathrm{Hg}_{1-\mathrm{x}} \mathrm{Cd}_{\mathrm{x}} \mathrm{Te}$," unpublished internal Honeywell document compiled by the research staff at the Honeywell Corporate Research Center, Hopkins, Minnesota, First Edition, May 1970.

Uncooled Infrared Imaging Arrays and Systems, Volume 47 of Semiconductors and Semimetals, ed. by Paul W. Kruse and David D. Skatrud (Academic Press, New York, 1997).

Paul W Kruse, Uncooled Thermal Imaging Arrays, Systems, and Applications , Tutorial Texts in Optical Engineering, Volume TT51 (SPIE Press, 2001).

\section{Chapters}

Paul W. Kruse, "Indium Antimonide Photoconductive and Photoelectromagnetic Detectors, Chapter 2 in Volume 5 of

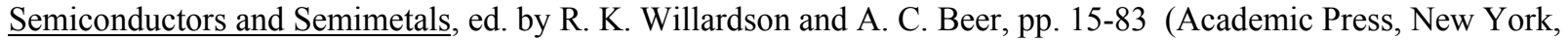
1970).

P. W. Kruse, "The photon detection process," Chapter 2 in Optical and Infrared Detectors Volume 19 Topics in Applied Physics, ed. By R. J. Keyes, pp. 5-69 (Springer-Verlag, 1980)

P. W. Kruse and J. F. Ready, "Nonlinear Optical Effects in $\mathrm{Hg}_{1-\mathrm{X}} \mathrm{Cd}_{\mathrm{X}} \mathrm{Te}$," Chapter 4 in Vol. 16 of Semiconductors and

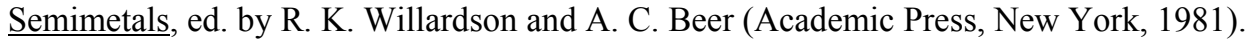

G. A. Gordon, R. L. Hartman and P. W. Kruse, "Imaging Mode Operation of Active Near-Millimeter Wave Systems," Chapter 7 of Infrared and Millimeter Waves V4: Millimeter Systems, edited by Kenneth J. Button, pp. 327-352 (Academic Press, 1981).

Paul W. Kruse, "The Emergence of Mercury Cadmium Telluride as a Modern Infrared Sensitive Material," Chapter 1 in Vol. 18 of Semiconductors and Semimetals, ed. by R. K. Willardson and A. C. Beer, pp. 1-20 (Academic Press, New York, 1981).

William L. Wolfe and Paul W. Kruse, "Thermal detectors," Chapter 19 in Handbook of Optics: Fundamentals, techniques, and design, Volume 1, ed. by Michael Bass, Optical Society of America (McGraw-Hill, 1994).

Paul W. Kruse, "Principles of Uncooled Infrared Focal Plane Arrays," Chapter 2 Uncooled Infrared Imaging Arrays and $\underline{\text { Systems, }}$ Volume 47 of Semiconductors and Semimetals, ed. by Paul W. Kruse and David D. Skatrud, pp. 17-44 (Academic Press, New York, 1997).

Paul W. Kruse, Application of Uncooled Monolithic Thermoelectric Linear Arrays to Imaging Radiometers," Chapter 10 in Uncooled Infrared Imaging Arrays and Systems, Volume 47 of Semiconductors and Semimetals, ed. by Paul W. Kruse and David D. Skatrud, pp. 297-138 (Academic Press, New York, 1997). 


\section{Publications \& Presentations}

Paul Kruse has at least 55 publications in scientific journals and at least 90 oral presentations at professional society meetings. Most of these are on $\mathrm{HgCdTe}$ or uncooled detector science and technology, including a number of invited presentations at SPIE symposia.

\section{Patents}

2,892,096, “Image Intensifiers," June 23, 1959

2,928,006, "Radiation Amplifiers," March 8, 1960

2,997,630, "Holding Switch,” August 22, 1961

3,526,801, "Radiation Sensitive Semiconductor Device," September 1, 1970

3,723,190, "Process for Preparing Mercury Cadmium Telluride," with J. L. Schmit, March 27, 1973

4,136,318, “Spin-Flip Raman Laser with Increased Tuning Range and Increased Frequency,” January 23, 1979

4,316,147, "Apparatus for Determining the Composition of Mercury Cadmium Telluride and Other Alloy Semiconductors," with M. A. Kahn and J. F. Ready, February 18, 1982

4,654,622, "Monolithic Integrated Dual Mode IR/MM-Wave Focal Plane Sensor," with N. A. Foss and R. A. Wood, March 31, 1987

4,970,395, "Wavelength Tunable Infrared Detector Based upon Super-Schottky or Superconductor-InsulatorSuperconductor Structures Employing High Transition Temperature Superconductors," November 13, 1994

5,293,041, “Thin Film Pyroelectric Imaging Array,” March 8, 1994

\section{Honors}

H. W. Sweatt Award, 1966, from Honeywell, for Outstanding Technical Accomplishment for development of HgCdTe IR detector technology

Alan Gordon Award, 1981, from SPIE, for outstanding contributions to practical development of HgCdTe IR detector technology

Outstanding Civilian Service Medal, 1983, from the Department of the Army, for contributions to the Army Scientific Advisory Panel and the Army Science Board

Henry Levinstein Award, 1999, from the Military Sensing Symposia, for his leadership roles in HgCdTe and uncooled microbolometer technology

Fellow, American Physical Society and Optical Society of America

Associate Fellow, American Institute of Aeronautics and Astronautics

Senior Member, IEEE

\section{Government Panels and Advisory Committees}

Army Scientific Advisory Panel, 1965-1977

Proc. of SPIE Vol. $870487041 \mathrm{~F}-10$ 
Army Science Board, 1978-1982, 1985-1990

Army Combat Developments Scientific Advisory Group, 1965-1968

Ground Warfare Panel, President's Scientific Advisory Committee, 1968-1972

Vietnam Panel, President's Science Advisory Committee, 1971-1972

NATO Review Panel, President's Science Advisory Committee, 1971-1972

Committee on Physical Sciences, Advisory Board on Military Personnel Supplies, National Research Council, National Academy of Sciences, 1969-1971

Committee of Materials for Radiation Detection Devices, National Materials Advisory Board, National Research Council, National Academy of Sciences, 1971-1972

Army Countermine Advisory Committee, National Research Council, National Academy of Sciences, 1971-1972

Army ERADCOM Technology Panel, 1975-1976

Army Near-Millimeter Wave Technology Base Development Study, 1977-1978

US/USSR Technology Balance Assessment Study, Naval Research Advisory Committee, 1979-1980

Committee on Chemical and Biological Sensor Technology, National Research Council, National Academy of Sciences, 1983-1984

Co-chair, Army Research Office Workshop on Submillimeter Wave Detection, 1985

Chair, Army Research Office Working Group on Automatic Target Recognition, 1994

Technical Advisor, Infrared Detector Array Development, NASA Jet Propulsion Laboratory, Pasadena, CA, 1993-1996

Professional Society Activities

Planning Committee, Third International Conference on Photoconductivity, 1968-1969

Electronic Materials Committee, Institute of Metals Division, Metallurgical Society, American Institute of Mining, Metallurgy, and Petroleum Engineering, 1968-1971

Advisory Committee, Far Infrared and Submillimeter Waves Technical Group, Optical Society of America, 1977-1979

Editorial Advisory Board Member for three scientific journals:

Optics Letters, 1977-1979

Infrared and Millimeter Waves, 1978-1989

Infrared Physics and Technology, 1978-????

Advisory Panel, DARPA/URI Submicron Heterostructures of Diluted Magnetic Semiconductors, 1986-1989

Technology, Manufacturing and Infrastructure Committee, American Electronics Association, 1990-1993

Proc. of SPIE Vol. $870487041 \mathrm{~F}-11$ 


\title{
Appendix B
}

\section{Commentary by Dr. Paul W. Kruse, Jr. Regarding the Growth, Treatment and Evaluation of Mercury Cadmium Telluride by the Quench/Anneal Process}

\begin{abstract}
Paul Kruse prepared this commentary on the early HgCdTe effort at the Honeywell Corporate Research Center, covering the period 1960-1967. This commentary was prepared probably around 1980.
\end{abstract}

In 1960 I began a Honeywell project at the Corporate Research Center to develop an intrinsic 8-14 $\mu \mathrm{m}$ infrared detector. The key to this was to find a semiconductor material whose forbidden energy gap was approximately one-tenth of an electron volt at the operating temperature of liquid nitrogen, 77 degrees Kelvin. At that time there were several materials in the scientific literature that gave some promise but no material was sufficiently well understood to indicate it to be the best choice. Accordingly, our first investigations were of the material mercury selenide.

In late 1960 we received a Request for Proposals from the United States Air Force, the objective of which was the same as we had been working towards on Honeywell funds. Accordingly, we wrote a technical proposal in competition with many other companies and eventually were awarded the contract. This contract began in February of 1961. Initially, under the contract, we examined mercury selenide and found it to be semi-metallic; therefore, it was of no use as an intrinsic 8-14 $\mu \mathrm{m}$ infrared detector. We then looked, for a short time, at mercury telluride and found it also to be semi-metallic and selected as our third choice the semiconductor alloy mercury cadmium telluride (HgCdTe).

We began our effort to grow $\mathrm{HgCdTe}$ either in late 1961 or early 1962. At that time there was a paper in the scientific literature which had been published in 1959 by four English scientists, Lawson, Nielsen, Putley and Young who stated that $\mathrm{HgCdTe}$ was an alloy semiconductor with an energy gap which could be adjusted by adjusting the cadmium telluride to mercury telluride ratio during the process of forming the compound. The data in the Lawson, Nielsen, Putley and Young paper were very scarce, but from one figure in the paper it could be deduced that the ideal composition was an alloy of 10 percent cadmium telluride and 90 percent mercury telluride. Because mercury cadmium telluride is written chemically as $\mathrm{Hg}_{1-\mathrm{x}} \mathrm{Cd}_{\mathrm{x}} \mathrm{Te}$, an alloy of 10 percent cadmium telluride and 90 percent mercury telluride corresponds to $\mathrm{x}=0.1$. Therefore, we began our initial investigation by attempting to verify that $\mathrm{x}=0.1$ was the proper composition for an 8-14 $\mu \mathrm{m}$ intrinsic infrared detector.

There were three parts to our experimental investigations. First, we had to develop a technique for growing $\mathrm{HgCdTe}$ crystals. Second, we had to measure their electrical and optical properties. Third, we had to make infrared detectors from the crystals and evaluate these detectors by standard techniques.

Let me describe first the difficulties of growing the crystals. It is well known that mercury has a high vapor pressure even at room temperature and it becomes enormous at elevated temperatures. Furthermore, mercury vapors are poisonous to man. Therefore, we were faced immediately with the problem of containment of the mercury vapor during the growth of a crystal of $\mathrm{HgCdTe}$ from the elements mercury, cadmium and tellurium. We realized it would not be possible to employ the standard Czochralski crystal growth technique used in other materials such as germanium and silicon in an open tube atmospheric pressure system. We chose therefore to grow by a modified Bridgman technique. This required the sealing of the elements mercury, cadmium and tellurium within an ampoule, heating them above the liquidus temperature to cause reaction, then lowering the ampoule slowly through a freezing plane.

Our first problem was the selection of a material for the ampoule of sufficient strength to withstand the extremely high mercury vapor pressure, yet not react with the elements at the elevated temperature. We chose quartz and we sought suppliers of very thick-walled quartz. Eventually we found one-half inch interior diameter quartz tubing whose wall thickness of several millimeters was sufficient in principle to withstand the extremely high vapor pressure of mercury at the reaction temperature, many tens of atmospheres pressure. Using quartz-blowing techniques, we fabricated ampoules from the thick-walled quartz by drawing one end of the ampoule to a conical tip and sealing the other end after the elements were loaded. We devised a plug technique in which a solid piece of quartz whose exterior diameter was slightly less than the interior diameter of the quartz ampoule was loaded into the end of the ampoule and sealed to the ampoule by quartz-blowing techniques. Into this ampoule we loaded the elements mercury, cadmium and tellurium. 
It was necessary to preserve stoichiometry between the elements, that is, to have the sum of the mercury and cadmium atoms equal the tellurium atoms within the crystal. Thus, it was necessary to load an excess amount of mercury into the ampule to account for the amount of mercury which filled the void within the ampoule because of the extremely high vapor pressure of mercury. The only way to determine the optimum amount of excess mercury was by experiment.

A second major problem was the determination of the proper $\mathrm{x}$ value to give an 8-14 $\mu \mathrm{m}$ infrared detector at the operating temperature of 77 degrees Kelvin. As stated earlier, the Lawson, Nielsen, Putley and Young paper indicated that a 10 percent alloy, that is, $\mathrm{x}=0.1$, was the proper amount. We learned through our experiments over a period of about two years that that was incorrect, and that the proper $x$ value was 0.2 or, more precisely, 0.205 . Now that fact, the optimum value, could only be determined from experiments on crystals and, of course, the initial crystals were oriented toward an $\mathrm{x}$ value of 0.1 . Therefore, it was necessary to iterate the crystal growth many times at different composition values.

Furthermore, the phase diagram of $\mathrm{HgCdTe}$ was such that the liquidus and solidus lines did not coincide. What this meant was that during freezing of a molten solution of $\mathrm{HgCdTe}$ there would exist segregation such that the first-tofreeze portion would be richer in cadmium telluride than the last-to-freeze. This non-uniformity in $\mathrm{x}$ value extended in all directions through the crystal, not only longitudinally but laterally.

Another major problem was determining the $\mathrm{x}$ value of a given sample of $\mathrm{HgCdTe}$. There were no good standards to use. Eventually over a period of several years we developed the density method of evaluating the crystals. Here the density, measured by Avogadro's method using a specifically selected fluid, gave an accurate measure of the composition. In arriving at that technique we evaluated other techniques including the X-ray lattice constant measurement and the electron beam microprobe.

Another problem in the growth of the crystals was a dendritic structure that appeared in the crystals after they were grown. It was determined that there was a very fine lattice, a sort of egg-crate structure, within the crystal, in which the walls of the egg-crate had a much higher $\mathrm{x}$ value than the material between the walls. This type of behavior had been found in materials which exhibit a phenomenon known as constitutional supercooling during growth. Therefore, it was necessary to devise a technique which avoided or removed the effects of constitutional supercooling, that is, the dendritic structure.

We therefore devised the following method of growth. First, we loaded the mercury, cadmium and tellurium into the thick-walled quartz ampoule. We evacuated the ampule on a vacuum system and sealed the end of it with a quartz plug. We then inserted the ampoule into a furnace which rocked the material within it, that is, the mercury, cadmium and tellurium, back and forth through an arc of 45 degrees in either direction, pivoted transverse to the longitudinal axis of the crystal. We rocked this back and forth as we heated the crystal above the liquidus temperature. This was not a standard technique used in the semiconductor industry. We devised this especially for $\mathrm{HgCdTe}$ in order to make sure that the molten solution of $\mathrm{HgCdTe}$ was thoroughly mixed.

In order to avoid the effects of explosions, we had many precautionary procedures. For example, we went through a careful selection process on the quartz tubing as it arrived from the factory. We looked for air streams in the quartz and those pieces that exhibited air streams we discarded. We looked for uniformity in the inner diameter, uniformity of the wall thickness, and concentricity. We obtained quartz from various suppliers and evaluated it. We compared natural with synthetic quartz. We also worried about the effects of impurities being leached out of the quartz into the molten HgCdTe. Therefore we had to select only high purity quartz and we had to examine the purity of the crystals grown in quartz from various vendors.

We used a metal pipe into which we fitted the ampoule to contain the fragments of quartz should an ingot explode. The pipe containing the ampoule was loaded into the rocking furnace. The rocking furnace was contained in a large explosion-proof vessel made from a section of well casing. This in turn had a vent going to the roof of the building so that the vapors in the event of an explosion would be vented outside the building and therefore not constitute a hazard to the health of the personnel within the building. 
We learned all of these things through a series of experiments requiring several years. For example, before we employed the steel well casing to contain the rocking furnace, we used a box made from plywood which we had screwed together at the edges. An explosion occurred which loosened the walls of the box. Mercury vapor escaped into the laboratory and contaminated it. Since mercury is a poison, it was not possible to work in that laboratory until it had been removed. We used a mercury monitor and would move into the laboratory for a very short time, wash a portion of the floor, walls and ceiling, and then depart the laboratory as the vapor pressure due to the disturbed mercury rose. Thus we were able to clean the laboratory entirely, but only in very short stretches of time lasting over a period of weeks or months. We eventually repainted the entire laboratory to cover up any remaining mercury.

In order to avoid the problem of dendritic growth caused by constitutional supercooling, we went to a two-stage crystal growth process. In the first stage we reacted the elements within the ampoule in the rocking furnace. We then removed the ampoule from the rocking furnace and loaded it into a second furnace, the axis of which was oriented vertically. This furnace was mounted on a drill press stand such that it was possible to lower the ampoule through a freezing plane at the bottom of the furnace. We knew in principle that if we could lower it slowly enough through a steep enough temperature gradient, we could avoid constitutional supercooling. Therefore, we devoted our attention toward devising a geometry with an extremely steep temperature gradient at a very slow lowering rate. In fact, at one time we were lowering the ingots from the interior of the hot furnace to a water bath immediately at the bottom of the furnace.

We had an accident in June, 1964, which was fortuitous. We were lowering the ingot through a steep temperature gradient very slowly, and this was taking place automatically over a weekend. Sometime during that weekend the Variac controlling a portion of the furnace burned out. As a result, the upper part of the ingot which had already been reacted in the rocking furnace and which was supposed to be at a temperature in the vertical furnace above the liquidus temperature, in fact was annealed at a temperature somewhat below the solidus temperature; approximately one-half the ingot was lowered through the freezing plane but the upper half was annealed at this temperature somewhat below the solidus.

When we discovered that this had happened after returning to work over the weekend we believed this ingot to be a failure. Therefore removed it from the furnace and set it aside. Several months later Bernice Johnson, a technician on the project, decided to examine this ingot which had been set aside. In so doing she discovered that the upper half of this ingot did not have the dendritic structure which previous ingots had exhibited. We therefore decided to conduct further tests on this annealed portion of this ingot and determined that it had excellent electrical and optical properties.

As a result of this "happy accident" we incorporated a high temperature anneal into our standard method of crystal growth. This was later termed a "high temperature recrystallization" because the ingots so formed were not only free from dendrites but also had large single crystal regions.

Later on, in the period roughly 1965-1967, we developed the low temperature anneal process. By this time the original Air Force contract had expired, having been replaced by a new one, and also a DARPA one, and Joseph L. Schmit had replaced me as the principal investigator.

We realized that $\mathrm{HgCdTe}$ was a defect semiconductor in which deviations from stoichiometry controlled the purity. Accordingly we began low temperature annealing experiments, both on the entire ingot and on pieces cut from it, in which the partial pressure of mercury over the $\mathrm{HgCdTe}$ was controlled. These experiments, which lasted several years, were successful and have been incorporated into the standard "quench/anneal" method of crystal growth.

Let me now speak of the second phase of our project which was to evaluate the electrical and optical properties of the ingots which we had grown. Our standard measurements that we conducted upon the ingots were Hall effect and resistivity experiments as a function of temperature from 4 degrees Kelvin to room temperature and optical transmission measurements at 4 degrees Kelvin, 77 degrees Kelvin, and room temperature. It is possible to determine the forbidden energy gap by the Hall effect and resistivity measurements, to determine the impurity content from Hall effect and resistivity measurements, and to determine the electron and/or hole mobility from Hall effect and resistivity measurements. 
The optical transmission measurements provide the forbidden energy gap and the temperature dependence of the gap. It is necessary that the results obtained from the Hall effect and resistivity measurements correlate with the results obtained from the optical measurements. This turns out to be difficult if the sample is non-uniform in its properties and if different samples from the same ingot are used for the Hall effect and resistivity measurements and for the optical transmission measurements. Because our early ingots of $\mathrm{HgCdTe}$ were non-uniform in composition, the results of the electrical and optical measurements were very confusing. For example, the optical absorption edge, instead of being very smooth, exhibited a jagged appearance. The Hall effect and resistivity curves did not exhibit the classical appearance for an n-type or a p-type semiconductor, but instead had very strange shapes, for example, exhibiting a double cross-over for p-type material.

It took several years of development before it was possible to obtain crystals of $\mathrm{HgCdTe}$ which were sufficiently uniform in composition and purity so that the electrical and optical properties were those to be expected from a uniform sample. Indeed, it was not until the late 1960's, in work done by Walter Scott of the Honeywell Corporate Research Center, that it was determined that a material having a p-type core and an n-type exterior would exhibit some of the confusing Hall effect and resistivity curves. This material was termed lightly doped p-type.

Our third major effort was concerned with preparing and evaluating infrared detectors made from the $\mathrm{HgCdTe}$ crystals. Here we had first of all to develop an optical Dewar in which to mount the elements, and secondly, we had to prepare and evaluate the elements.

Our first Dewars were liquid helium laboratory-type ones with windows which were transparent to infrared radiation out to a wavelength of approximately $15 \mu \mathrm{m}$. Since these were laboratory Dewars, it was necessary to develop a sealing process for the windows. However, it was also necessary that we develop a Dewar suitable for use at liquid nitrogen temperature, 77 degrees Kelvin, which could be used in the field. The problem here had to do with selection of a window material which could be bonded in some fashion to the body of the Dewar. We looked at various materials including cadmium fluoride, several of the IRTRAN's, KRS-5, silver chloride, germanium, and silicon, searching for a material which we could seal to glass, but in any event something which we could at least epoxy to the body of the glass Dewar.

We had to devise methods for preparing sensitive detector elements from the crystals. Here we had to devise a suitable lapping and etching procedure. The etch had not only to remove the scratch marks from the lapping, but it also had to leave the surface with a suitably low recombination velocity. We found that a bromine-methanol etch was a good one for this purpose.

We had to find a substrate material upon which the sensitive element could be mounted. This material had to be a good thermal conductor and it had to have a thermal coefficient of expansion between room temperature and liquid nitrogen temperature which closely matched that of the $\mathrm{HgCdTe}$. We found that germanium was such a material.

We had to devise a method for cementing the crystal of HgCdTe to the substrate. This cement had to withstand the temperature shock and it also had to have a good thermal conductivity and be capable of expanding or contracting with temperature to match the thermal expansion coefficient of the substrate material and $\mathrm{HgCdTe}$.

We also needed a method of providing electrical contact to the sample. This meant finding a suitable solder. We investigated several types including selected indium solders before finding one that would work.

Having then the sensitive element of $\mathrm{HgCdTe}$ on its substrate mounted in the Dewar and with electrical connections to it, we then evaluated its performance as an infrared detector material. We poured liquid nitrogen into the central well of the Dewar and measured the black body detectivity, the black body responsivity, the spectral responsivity and the spectral detectivity on laboratory equipment. The spectrometer that we used for the spectral measurements was a standard laboratory instrument which we had modified in order to place the detector at the exit port. The black body test apparatus was not available commercially; it had been built at Honeywell for use on an earlier detector development project and was modified by us for use in our HgCdTe project. 
The design of a suitable low-noise electrical amplifier was a time-consuming process. Whereas many types of infrared photoconductive detectors have high resistances, the $\mathrm{HgCdTe}$ photoconductive detectors that we were preparing and evaluating did not. This made it difficult to devise an amplifier which would electrically amplify the signal without introducing additional noise than that already present in the material. So called " $1 / \mathrm{f}$ " noise was a problem due to the electrical bias on the sample. We wanted the detector to be limited by a fundamental noise mechanism such as generation-recombination noise or Johnson noise. Thus we spent much effort in devising techniques to minimize " $1 / \mathrm{f}$ " noise and developing a low-noise electrical amplifier. Having done so it was possible to prepare and measure the properties of the $\mathrm{HgCdTe}$ detectors, both on the black body test apparatus and the spectrometer, which approached the fundamental background noise limit.

As our crystal growing techniques improved and the samples became more uniform, as we learned the proper $\mathrm{x}$ value, as we developed the annealing procedures, as we were able to understand the electrical and optical properties and correlate them with the detector properties, over a period of several years we gradually developed the detector technology to the point at which we were beginning to make HgCdTe photoconductive detectors operating in the 8-14 $\mu \mathrm{m}$ spectral interval at liquid nitrogen temperature which exhibited performance suitable for use in military applications. We arrived at this point in 1964, although the yield of good detectors was extremely low.

We then invited a representative from the Honeywell Radiation Center in Lexington, Massachusetts, Mr. Ray Russell, to visit us. We taught him how to prepare infrared detector elements from the HgCdTe crystals. He took this technology back with him to the Honeywell Radiation Center and began to prepare detectors from crystals supplied by us. It was approximately two years later, in 1967, that we began transferring the crystal growth technology to the Honeywell Radiation Center.

It will be seen from all of this that the development of the technology of $\mathrm{HgCdTe}$ suitable for use in infrared detectors was not a simple and straightforward task. There were many, many problems which we had to solve in our laboratory because of the lack of information about $\mathrm{HgCdTe}$. There were other investigators working in the field in the early 1960's, and publishing data in the scientific literature. Nevertheless we found it necessary to develop these procedures all on our own because data were lacking.

The crystal growth technique that we devised in the early 1960's, termed "quench/anneal," is the basis for that in use today at the Honeywell Electro-Optics Center (formerly known as the Honeywell Radiation Center). Of course, over a period of more than a decade, refinements have been introduced, such as the rapid quench from the melt.

Nevertheless, the early work at the Corporate Research Center is the foundation for the Honeywell Electro-Optics Center quench/anneal process.

\section{Appendix C}

\section{Letter from Paul Kruse to Paul R. Norton, July 16, 1999}

Dear Paul,

Thanks for the copies of your paper on $\mathrm{HgCdTe}$ detectors and detectors for the next millennium. I would like to correct some misstatements in the first paragraph of the former.

The sequence of events was as follows: Lawson, Nielsen, Putley and Young published one paper, which is your reference no. 1. Lawson, Nielsen and Young (but not Putley) also obtained a patent. The data from their paper and patent indicated that a composition of $\mathrm{x}=0.10$ would correspond to an energy gap of $0.1 \mathrm{eV}$. Their results were not encouraging; they abandoned ( $\mathrm{Hg}, \mathrm{Cd}) \mathrm{Te}$ in favor of $\mathrm{Ge}: \mathrm{Hg}$.

I had an internally funded project at Honeywell to explore the possibility of an intrinsic 8-14 $\mu \mathrm{m}$ photon detector operating at $77 \mathrm{~K}$. I also had a series of discussions at that time about recombination mechanisms with John Blakemore at Honeywell. With Don McGlauchlin and Rich McQuistan of Honeywell, I was working on the manuscript of Elements of Infrared Technology, most of which was done in 1961. I wrote chapters 6 through 10. This included 
section 9.5, "Means of Achieving Photon Noise Limited Performance." Included here was a discussion of recombination mechanisms, including Figures 9.18 and 9.19 on the dependence of Auger and radiative lifetimes upon temperature in a hypothetical direct gap semiconductor having a band gap of $0.086 \mathrm{eV}$ at $77 \mathrm{~K}$, corresponding to a long wavelength limit of $14.5 \mu \mathrm{m}$.

In 1960, the Air Force Avionics Lab issued an RFP for research leading to a photon detector operating in the 8$14 \mu \mathrm{m}$ region at $77 \mathrm{~K}$. I submitted a proposal, which won Contract AF33(616)-7901. Thad Pickenpaugh was the technical monitor. He said that 35 proposals were submitted. Mine had the technical arguments regarding a direct gap and the competition between the lifetime mechanisms.

The contract began in February, 1961. I was the project leader, assisted by Don Blue and Jim Garfunkel. (Joe Schmit joined the effort in 1965 when Don Blue left.) At that time, it was thought that HgSe and HgTe were small gap semiconductors. We began with $\mathrm{HgSe}$; it had been speculated in the literature that it had a gap of $0.1 \mathrm{eV}$. We synthesized single crystals, did $\mathrm{R}_{\mathrm{H}} \& \rho$ vs $\mathrm{T}$, did transmission measurements, analyzed the data, and showed that it was a semimetal. We then showed that $\mathrm{HgTe}$, which was thought to have a gap of $0.02 \mathrm{eV}$, was also a semimetal. Some people thought that they had seen photoconductivity in these materials. We were able to prove that what they saw was really a bolometer signal.

(Hg,Cd)Te was our third choice. We began our material synthesis efforts in 1962, using a modified Bridgman process, dropping the liquid very slowly through a steep temperature gradient in an attempt to avoid constitutional supercooling which was causing a sort of microscopic dendritic lattice of high-x material with low-x material in between. We saw true photon effects very soon, but it was clear that the material was very nonuniform.

We had a lucky break over a weekend. The vertical furnace we were using for Bridgman growth had three zones. A fuze blew on one zone, causing the portion of the crystal which had been dropped through the freezing plane to undergo a high temperature anneal. That caused a solid state recrystallization which removed the dendrites, providing lots of usable material. We numbered the crystals according to the date they were solidified; the good one was 61864, i.e., June $18,1964$.

We had been evaluating our material at $77 \mathrm{~K}$ in the photoconductive mode. I can still picture that relatively enormous signal when we first made a photoconductor from 61864.

Beginning around 1963, our work had become classified Confidential. Texas Instruments, SBRC and elsewhere were watching our progress, but didn't think much of it. Their efforts were largely on extrinsic Ge. However, Henry Shenker of NRL called a classified meeting at NRL in November of 1964. At that time we presented our latest data on photoconductors made from 61864 . I think that $\mathrm{D}_{\lambda}{ }^{*}$ at $10 \mu \mathrm{m}$ and $77 \mathrm{~K}$ was about $5 \times 10^{9} \mathrm{~cm} \mathrm{~Hz}^{1 / 2} / \mathrm{W}$, but am not certain of that. Prior to that meeting, none of the detector houses, including SBRC and TI, had a (Hg,Cd)Te program. All of them afterwards began ones.

We had been working closely with Honeywell in Lexington, having transferred to them a $77 \mathrm{~K} \mathrm{InSb}$ photoconductive detector. They were using them in a mapper they were delivering for the Army Mohawk reconnaissance aircraft. The mapper was in production. We gave them a piece of 61864 and also began delivering $(\mathrm{Hg}, \mathrm{Cd}) \mathrm{Te}$ detectors to them. We grew crystals for them, from which they made arrays. All this began in about 19641965.

So the first photoconductive $(\mathrm{Hg}, \mathrm{Cd}) \mathrm{Te}$ detectors were made by our laboratory and the first production arrays were made by Honeywell in Lexington. Contrary to your statement, TI had no program in 1964 and did not make photoconductive $(\mathrm{Hg}, \mathrm{Cd}) \mathrm{Te}$ at that time.

Enclosed is some related information.

Paul 


\section{Appendix D}

\section{Remarks by Paul Kruse upon Receiving the 1999 Henry Levinstein Award}

Dr. Paul W. Kruse was presented with the Henry Levinstein Award "for outstanding technical leadership and management of infrared technology." The award was presented in conjunction with the annual IRIS Detector Specialty Group Meeting held in Lexington, Massachusetts on August 18-19, 1999. Mark Gurnee of Lockheed Martin IR Imaging Systems prefaced the presentation with some recollections about the accomplishments of Paul's 45-year career, which was spent mostly at the Honeywell Corporate Laboratory in Bloomington, Minnesota. Mark reminded the audience that Paul pioneered two major detector innovations, $\mathrm{HgCdTe}$ and uncooled microbolometer arrays, both of which revolutionized infrared technology. Paul made the following remarks after receiving the award.

Thanks to Mark Gurnee for his kind remarks and to Jim Robinson and the committee for presenting me with the Henry Levinstein Award.

I remember Henry very well, a very fine and likeable person who was in the Physics Department of Syracuse University. Many persons for whom he was thesis advisor received their Ph.D. for the development of new types of infrared detectors. Among those I remember from the early days are Werner Beyen, who went to Texas Instruments, Don Bode, to Santa Barbara Research Center, and Marv Lasser, who became Chief Scientist of the Army.

I've had a wonderful life during my career in infrared technology. When I graduated in 1954 and began working at Farnsworth Electronics in Fort Wayne, Indiana, near-infrared imaging was accomplished using image converters, developed as rifle sights in World War II. They used illuminated sources, which were lamps employing Corning 2540 filters that blocked visible light but transmitted near-infrared radiation. The Army Night Vision Laboratory, in an effort directed by Johnny Johnson, developed image intensifiers, which did not require artificial illumination. During the early days of the Vietnam War, the "starlight scope" was deployed. It consisted of three image intensifiers using fiber optics to couple the output from the phosphor of the first to the photocathode of the second, and similarly from the second to the third. They were considered so valuable and secret that soldiers were directed to smash them against a tree rather than allowing them to be captured by the enemy.

Two subsequent advances occurred which were keys to today's image intensifiers. The first was channel multipliers, which provided electron gain within a tube. The second was the development of negative electron affinity photocathodes, first announced by Philips of Eindhoven, and today widely employed using GaAs as the photocathode material. The development of these single-tube image intensifiers has been an outstanding success story. I played no part in it.

The other outstanding success story has been in thermal imaging. When I left school in 1954, thermal imaging using semiconductor materials required two-dimensional scanning, since the detector element (now referred to as a pixel) consisted of just a single element. The materials in use were largely doped Ge, including Ge:Au whose response extended to about $8 \mu \mathrm{m}$, and Ge:Hg, which extended, as I recall, to about $12 \mu \mathrm{m}$. Ge:Au operated at $77 \mathrm{~K}$, whereas Ge:Hg usually operated in a double Dewar at $4 \mathrm{~K}$. Even longer wavelengths, to about $40 \mu \mathrm{m}$, were obtained by Ge:Zn at $4 \mathrm{~K}$. For the mid-IR, PbSe was available. At Farnsworth I worked on PbTe, which was thought to extend to even longer wavelengths than $\mathrm{PbSe}$, but in reality it did not. PbSe could operate at room temperature, but the best performance was at $77 \mathrm{~K}$.

Walker of Siemens discovered that III-V's were semiconductors in the mid-1950's. In fact he was granted a patent on all their applications (including GaAs!) but no one honored it because it could not be enforced. InSb was investigated beginning in the mid-1950 as a mid-IR material operating at both room temperature (PEM cell) and at $77 \mathrm{~K}$ in either the photoconductive on photovoltaic mode.

HgCdTe came along in the mid-1960's, although it had first been investigated by Lawson, Nielsen, Putley and Young at RSRE in the UK in the late 1950's. Honeywell's Electro-Optics Division (then called the Honeywell Radiation Center) in Lexington, Massachusetts had a contract for the "Mohawk mapper;" the Mohawk was a twin-engine Army observation aircraft. The original mapper used photoconductive InSb, developed at Honeywell's Corporate 
Research Center, then in Hopkins, Minnesota. The first application of HgCdTe was as an LWIR replacement for MWIR $\mathrm{InSb}$ in the Mohawk mapper.

During the Vietnam War, Marv Lasser, Chief Scientist of the Army, organized a program entitled SEANITEOPS (Southeast Asia Night Operations) in which prototype thermal imaging equipment was tested in Vietnam, including $\mathrm{HgCdTe}$. It was at this time that Forward-Looking Infrared equipment (FLIR's) first appeared.

In the early 1970's, VLWIR emphasis shifted to extrinsic Si, e.g., Si:As, and later the BIB (blocked impurity band) concept became the basis for many extrinsic Si devices. The concept of the Common Modular FLIR, using PC HgCdTe as the detector module, was developed by NVL in the early 1980's. Today, these HgCdTe linear arrays are being replaced by very large Focal Plane Arrays.

All of these developments depended heavily on materials science and solid state physics. I participated in them. It was a very exciting time, because solid state physics grew enormously with the inventions of the transistor (1947) and the integrated circuit ( 1960). IR detector development depended heavily on the solid state capabilities of many individuals and the availability of integrated circuit process technology.

When I left school in 1954, uncooled detectors were largely single pixel thermistor bolometers, also radiation thermopiles with one pixel. There were other approaches to imaging, such as the absorption edge image converter and the Evaporagraph, but they were impractical. Golay cells were useful as single-pixel laboratory devices but not as fieldable units.

In early 1980's, both Texas Instruments and Honeywell's Corporate Lab (probably called the Sensors and Signal Processing Lab or something similar at that time) began investigating uncooled imaging arrays. Funding of the developments under HIDAD (High Density Array Development) began in 1987. Prior to that each company was funded by NVL and DARPA, TI beginning about 1980 and the Honeywell Corporate Lab about 1985. Beginning about 1989, both received funding under the LOCUSP (Low Cost Uncooled Sensor Program) program. The contracts were classified until June or July, 1992. During this same period the Honeywell Electro-Optics Division had a program similar to TI's, but it never received the level of funding of TI's.

Today the uncooled efforts have grown to become very large, thanks to Honeywell's licensing of the bolometer technology and strong funding from DARPA.

It was extremely exciting and gratifying to have been part of this effort. During our 45 years of marriage, Marge has been "Mrs. Inside" to my "Mr. Outside." She gave birth to our nine children and now is the grandmother of fourteen. She deserves this much as I do. Thank you.

\section{Appendix E}

\section{Letter from Paul Kruse to Dr. E. M. Banas, November 27, 2001.}

Paul wrote this note to his family that was attached to this letter: "The enclosed letter to Mike Banas is a brief summary of my life as a physicist. Mike received a Ph.D. in physics a year after I did from Notre Dame. For many years he has written a column in the quarterly magazine "Notre Dame" about Ph.D. graduates of the Physics Department. I have written him once or twice, many years ago. I decided that now was the time for a career summary. Please add this to your copy of my autobiography."

Dear Mike,

Having read about George Haas in your recent column, I decided to bring you up to date on what I have done and am still doing. You probably remember that I received the B.S., M.S. and Ph.D. degrees from Notre Dame in 1951, 1952 and 1954. My thesis advisor was Ed Coomes; the topic was field emission. Marge and I were married on January 23, 1954, one semester prior to my receiving the Ph.D. 
After graduation, I received only one job offer, from Capehart Farnsworth in Fort Wayne, IN. During the two years that I was there, the company changed ownership twice, and became part of International Telephone and Telegraph. It was there that I was introduced to solid state physics and infrared technology, the cornerstones of my career.

Marge and I moved back to Minnesota, where we both were originally from, in September, 1956, along with Paul II and Bob, both born in Fort Wayne. I went to work for Honeywell Corporate Technology Center in suburban Minneapolis, from which I retired in 1993. Honeywell had the "dual ladder" system, whereby a scientist or engineer could be promoted into technical management or could choose to remain an individual contributor and could thereby receive promotions equivalent in pay and prestige to management. I never wanted to be a manager, so stayed on the technical side; I retired as Chief Research Fellow, but "Chief" does not mean that I had anyone reporting to me in the sense of determining their performance and salaries. Over the 35 years I headed numerous research and development teams, but was not their manager.

I was extremely fortunate to participate in the evolution of solid state physics; (I dislike the APS nomenclature "condensed matter physics.") Most people think of solid state applications as initially transistor development and later integrated circuit development. That certainly is the major part, but the development of infrared detectors and focal plane arrays was a significant part. That was in my area of interest. For your information I am enclosing a copy of a brief talk which gave upon receiving the Henry Levinstein Award from the Detector Specialty group of IRIS - Infrared information Symposia, in 1999.

In addition to infrared detector development, which involves a lot of semiconductor materials development, I also spent eight years in nonlinear optics, a fascinating subject which is just now finding some applications. The latter effort was sponsored by the Office of Naval Research; other efforts of mine were sponsored by the Air Force Office of Scientific Research and the Army Research Office. These organizations sponsor what is termed "Basic Research" within the Department of Defense. I cite these to show that basic research is not only the province of universities, but is also within industrial laboratories.

Nearly all of my work was sponsored by government contracts; the Department of Defense was the primary sponsor. I wrote the proposals, was the "Principal Investigator," formed the teams, led the efforts, wrote technical reports, financial reports and final reports. I found that the objectives, goals and report requirements helped me greatly to focus the investigations.

In all these developments, mathematical analysis accompanied he laboratory development. I became very good at it. Also, I was directed toward determining the fundamental limits of the devices. I am not speaking of the electrical noise within the device, which I also investigated, but how well an ideal device could operate. In infrared detectors it is called the background fluctuation limit, which appears in several forms. I was one of the earlier investigators of this. In 1962 I co-authored Elements of Infrared Technology, published by John Wiley and Sons, which clearly helped my career. The book has been long out of print, but the other day I received a call from someone who asked whether I would autograph a copy when we meet next April.

In addition to the above book, I co-edited Uncooled Infrared Imaging Arrays and Systems, published by Academic Press in 1997, and am the sole author of Uncooled Thermal Imaging Arrays, Systems, and Applications, published by SPIE Press in June of this year. This is an expansion of a course which I have been teaching at SPIE meetings and at industrial and government laboratories since 1992. I have also published chapters on infrared detectors, millimeter wave detectors and nonlinear optics in six other books. I have something like 130 other oral and written publications and hold ten patents. I have been a Fellow of the American Physical Society and of the Optical Society of America since the 1970's. I have been a member of the Editorial Advisory Boards of Optics Letters, Infrared and Millimeter Waves and Infrared Physics and Technology. I have been on numerous national committees including 22 years on the Army Science Board, three years on subcommittees of the President's Science Advisory Committee, four committees of the National Research Council of the National Academy of Sciences and nine other national committees. 
I retired from Honeywell at age 65 in 1993. With seven other Honeywell retirees, in 1994 we founded Infrared Solutions, Inc., in suburban Minneapolis. This is a privately held company which develops and manufactures infrared imagers and imaging radiometers. Sales this year will be $\$ 7 \mathrm{M}$ and we are profitable with negligible debt. Sales last year were $\$ 5.3 \mathrm{M}$, so we are growing fats. I spent one-third of my time as Chief (and only) Scientist from 1994 to mid- 1998. I have also been a consultant, since retiring from Honeywell, for many industrial and government organizations, and this year as an expert witness for two law firms.

Enough of that, let me now discuss my family and our relationship to Notre Dame. Marge and I have nine children ranging in age from 30 to 47 . Eight are married and we have $16 \frac{1}{2}$ grandchildren. All of our children and their families live near here, with the exception of two who live in Louisville, KY. All except one of our children attended Notre Dame; Cate attended Marquette. Of the same eight, three married ND classmates and two married St. Mary's grads. Marge and I have been very active in the N.D. Club of Minnesota (even though marge is a graduate of St. Catherine's in St. Paul). I was the club president in 1974-75. Both of us spent about 20 years on the Alumni Schools Committee of Minnesota, which we headed for about 10 years. I was on the national Notre dame Alumni Board from 1979 to 1982, representing Minnesota, North and South Dakota and western Wisconsin.

Sincerely,

Paul W. Kruse

\section{Appendix F}

\section{Letter from Marion Reine on the Occasion of Paul Kruse's Retirement from Honeywell, Oct. 5, 1993}

October 5, 1993

Dr. Paul W. Kruse

Chief Research Fellow

Honeywell Inc.

Sensor and System Development Center

10701 Lyndale Avenue South

Bloomington, Minnesota 55420

Dear Paul,

All of your friends and colleagues here at Loral Infrared \& Imaging Systems (LIRIS) wish we could have arranged a business trip to enable us to be at your retirement celebration tonight. However, the frequency of our business trips to Minneapolis has dropped by orders of magnitude since we were acquired three years ago by Loral. Still we wanted to make our presence felt on this occasion, and to give testimony in some way to the enormous impact that your 37 year career at Honeywell has had on our whole business. So we do it through this letter.

Your pioneering research on new narrow-gap semiconductors in the early 1960's led to the establishment of mercury-cadmium telluride ( $\mathrm{HgCdTe}$ ) as today's preeminent infrared detector material. You grew the first ingots of $\mathrm{HgCdTe}$ in this country. Your early efforts, along with those of Don Long, Joe Schmit, and many others at the Honeywell Corporate Research Center in Hopkins, Minnesota, were central to the initial understanding of the physics and material science of this exotic semiconductor alloy, and were responsible for defining its exciting potential for reaching the theoretical limits for quantum infrared detectors. Your early work led directly to the founding of the Honeywell Radiation Center in Boston in 1963, which eventually evolved over the ensuing thirty years, through many name changes, to Loral Infrared \& Imaging Systems. And even though large two-dimensional arrays of LWIR HgCdTe photodiodes are now in manufacturing at LIRIS, we have still not fully realized all of the potential that this remarkable material holds for infrared detectors. 
I don't think that one can overestimate the importance of your early work on $\mathrm{HgCdTe}$. Bob Lancaster dropped into my office the other day to chat about your retirement from Honeywell, and he remarked that all of us here at LIRIS do what we do every day as a result of your seminal work on HgCdTe.

Your work in setting the foundation for our $\mathrm{HgCdTe}$ detector and systems business would have been enough of an achievement in itself for any one individual. But there is a long list of your major contributions to our business and to our technology.

For example, another important innovation that you made, this one more recently, was in the area of uncooled infrared arrays with your microbolometer detector architecture. In just a few years, you and your coworkers at Honeywell brought your concept to the stage of being one of today's two most important uncooled IR detector approaches. This accomplishment was recognized at the recent IRIS Detector Specialty Group Meeting in Boston, at which Andrew Wood accepted, jointly with Texas Instruments, the Herschel award for outstanding technological advancement in infrared detectors. Your uncooled detector approach is being exploited today at LIRIS as well as other infrared detector companies.

And there are still more contributions. You were one of the key leaders in bringing the dual-ladder system to Honeywell and establishing the rank of Honeywell Fellow, which we are still emulating at LIRIS. You did several forward-looking assessments of FLIR technology for Army thermal imaging applications in the 1970's, and these helped steer our systems business in the right directions. In the early 1980's you spent week after week in the witness stand, serving patiently and graciously as the expert witness on $\mathrm{HgCdTe}$ technology during our period of litigation. In fact, it seemed to me that you were the only person to have actually enjoyed anything about that whole episode. And I must mention the frequent committees that you headed or participated in, that visited our facility to help put our HgCdTe material growth and detector fabrication processes back on track. Your methods of leading a group were most effective in focusing discussion and emotion onto the technical issues. Your gentlemanly demeanor and good humor during those frequently contentious meetings were noteworthy and most appreciated.

Another technical area that you pioneered in Honeywell is the exploitation of high-temperature superconductivity for infrared detector applications. This is still in the development stage. Nevertheless, it is perhaps the most recent, though I'm sure not the last, example of your ability to do funded research that gets rapidly to the forefront of a new field.

I must mention one other technical area that you pioneered within Honeywell, that of nonlinear optical properties of $\mathrm{HgCdTe}$. In the late 1970's, Bob Lancaster grew some very long wavelength $\mathrm{HgCdTe}$ crystals for you, from which you made some of the first HgCdTe spin-flip Raman lasers. I remember going on a business trip with you to Exxon Research Laboratories in Linden, New Jersey to try to apply your HgCdTe spin-flip Raman laser to uranium isotope separation. In retrospect, it is fortunate that that trip was unsuccessful.

And finally, the body of your written work in infrared detector technology is both exceptionally large and exceptionally impressive. Your 1962 book became and remains a classic textbook for our industry. Your lucid review chapters on various topics in infrared detection are well known and highly regarded. Your Honeywell reports and memos are models of excellent technical writing. And given that we here at LIRIS have seen only a subset of your written work, one wonders when you found the time to write it all, and to write it all so well.

I have tried in this letter to recount the ways that your career at Honeywell has had an impact on our business and technology at LIRIS. In reviewing this subset of your accomplishments, one is struck both by their quantity and quality. But the way in which one accomplishes things is also important. And I think it must be emphasized here that you conducted your work in a way that inspired admiration and loyalty and at the same time created a strong sense of technical excitement. You were always a gentleman, always a professional, no matter how adverse or trying the circumstances. You helped others in their careers. Your career itself is a fine example of how a physicist can best contribute in industry. Your career has been and will continue to be a model for many others in Honeywell and LIRIS. Certainly I looked to you for advice and guidance many times during the past 24 years. 
So please accept the gratitude and good wishes from all your friends and colleagues at LIRIS on this occasion, including John Dehne, Jill Wittels, Mark Gurnee, Bob Lancaster, Steve Jamieson, Margie Weiler, Sato Iwasa, Neal Butler, and many others. We all benefit in some way from the fruits of your labors in your Honeywell years, and we all look forward to working with you in your new career as consultant.

Sincerely,

Marion B. Reine

Principal Engineering Fellow

Loral Infrared \& Imaging Systems

Lexington, Massachusetts

\section{Appendix G}

\section{Paul Kruse Obituary}

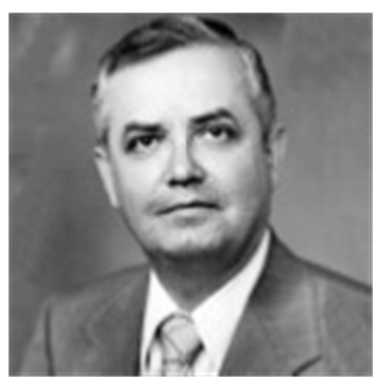

Paul Walters Kruse, Jr., age 84, of Edina, MN, died peacefully Oct. 22, 2012 at the St. Therese Southwest Memory Care facility in Hopkins, MN with Margaret Fitzpatrick Kruse, his wife of 58 years, at his side. Preceded in death by his father, Paul W. Kruse, and mother, Marie R. Kruse. Paul was born on Nov. 24th, 1927 in Hibbing, MN and grew up in Virginia, MN where his father was a mining superintendant for the Jones and Laughlin Steel Corp. Paul was drafted into the Army in 1945, serving at a Field Hospital unit in Taejun, Korea. He then attended the University of Notre Dame where he earned his bachelor's, master's and doctoral degrees in Physics. Paul went on to an exceptionally productive career with the Honeywell Corporation, becoming a published author and one of the world's foremost experts in optics and in semiconductor and infrared technology as well as a recipient of the inaugural H.W. Swett Award. Paul also served his country on the Army Scientific Advisory Panel and the President's Science Advisory Committee under President Nixon. He was a co-founder of Infrared Solutions, Inc. For all his accomplishments, though, Paul will be most fondly remembered for his faith, his humanity, and his devotion to his wife and family. He was the father to Paul II (Dianne), Bob (Cathy), John (Susie), Mary (Jon), Margaret, Charlie (Mary Jane), Tom (Kathy), Cate (Paul), and Bill (Tina). Paul also was a loving and devoted grandfather to 19 grandchildren and many nieces and nephews. After his retirement from Honeywell in 1993, Paul loved spending many happy hours with his grandchildren at his home in Edina with Marge. He enjoyed golf and was an avid reader, particularly passionate about aviation, science, and technology. Paul was exceedingly devoted to his Catholic faith as well as to Catholic education, serving on the School Board of St. Richard's Church in Richfield, the Board of Directors at Benilde High School, and the Alumni Association Board of Directors of the University of Notre Dame. Mass of Christian Burial will be at 11 AM on Friday, Oct. 26, 2012 at the Church of Our Lady of Grace at 5051 Eden Ave. in Edina followed by private interment at Resurrection Cemetery. Visitation will be at the Church of Our Lady of Grace from 5-7 p.m. on Thursday, Oct.25, 2012 and one hour prior to Mass on Friday.

Published in Star Tribune on October 23, 2012 


\section{Appendix H}

\section{"Why I Didn't Win the Nobel Prize in Physics"}

A light-hearted poem written by Paul Kruse for his family, probably written circa 2002

Every year, in the fall

I ask the mirror on the wall

"Mirror, Mirror on the wall,

Who is the Nobelist of all?"

And the Mirror answers every fall,

"Why of course it's you, Dr. Paul."

So I sit near the phone and await the call, But the phone is mute again this fall.

Until I learn they gave it to Fermi, So I ask the Mirror "How can this be?

They know how much that I take pride in developing mercury cadmium telluride. Why on earth did they take this action Of giving it to him for the chain reaction?"

Then the Mirror replies, "I know a lot. It's all because of the butterfly ballot. Fermi said, "When they voted for you They really meant me; they hadn't a clue."

"I want a recount," I say in anger.

"I want to count every chad that's a hanger. I want all the dimples, those little dents, To me it's the only thing that makes sense."

But then I think, "That's too much pride. It's better for physics if I step aside. If not, it pits the nuclear bunch Against infrared, that's my hunch."

And so every year I await the call. I'm sure it will come after all.

I'm writing to you, my family dear, To explain why I didn't win this year. All of you know I really should,

But I sacrificed it all for a higher good! 


\section{References}

1. John S. Blakemore, Semiconductor Statistics (Pergamon Press, 1962).

2. "HgCdTe: 50 Year Anniversary Session," Infrared Technology and Applications XXXV, SPIE International Symposium on Defense, Security + Sensing, April 13-17, 2009, Orlando, Florida; Proc. SPIE $\underline{7298, ~ 7298-2 S ~(2009) . ~}$

3. Tom Elliott, "Recollections of MCT Work in the UK at Malvern and Southampton," Invited Paper at "HgCdTe: 50 Year Anniversary Session," Infrared Technology and Applications XXXV, SPIE International Symposium on Defense, Security + Sensing, April 13-17, 2009, Orlando, Florida; Proc. SPIE 7298, 72982M (2009).

4. M. B. Reine, "History of HgCdTe Infrared Detectors at BAE Systems," Invited Paper at "HgCdTe: 50 Year Anniversary Session," Infrared Technology and Applications XXXV, SPIE International Symposium on Defense, Security + Sensing, April 13-17, 2009, Orlando, Florida. Proc SPIE 7298, 7298-2S (2009).

5. Joe Schmit, Paul Kruse and Ernie Stelzer, "Development of a $0.1 \mathrm{eV}$ bandgap semiconductor at the Honeywell Research Center (1959 - 1985)," Invited Paper at "HgCdTe: 50 Year Anniversary Session," Infrared Technology and Applications XXXV, SPIE International Symposium on Defense, Security + Sensing, April 13-17, 2009, Orlando, Florida. Proc SPIE 7298, 7298-2R (2009).

6. Ernest Putley, "Thermal Radiation and Its Applications," Chapter 7 in Cold War, Hot Science: Applied Research in Britain's Defence Laboratories 1945-1990, edited by Robert Bud and Philip Gummett (Harwood Academic Publishers, $1^{\text {st }}$ edition, November 1, 1999), pp. 185-218.

7. W. D. Lawson, S. Nielsen, E. H. Putley and Y. S. Young, "Preparation and Properties of HgTe and Mixed Crystals of HgTe-CdTe," J. Phys. Chem. Solids $\underline{9}, 325$ (1959).

8. William Donald Lawson, Stanley Nielsen and Alexander Scott Young, "Photosensitive Cells, Radiation Filters and Semiconductor Materials for Use in such Cells and Filters," UK Patent 859,588, Application Date Sept. 3, 1957; Published Jan. 25, 1961.

9. William Donald Lawson, Stanley Nielsen and Alexander Scott Young, "Photosensitive Cells, Radiation Filters and Semiconductor Materials for Use in such Cells and Filters," US Patent 2,953,690, Filed Sept. 3, 1958, Patented Sept. 20, 1960.

10. U.S. Air Force Contract AF33(616)-7901, performed at Honeywell Research Center, Hopkins, Minnesota; P. W. Kruse, Principal Investigator; T. D. Pickenpaugh, Air Force Technical Monitor.

11. P. W. Kruse, M. D. Blue, J. H. Garfunkel and W. D. Saur, "Long Wavelength Photoeffects in Mercury Selenide, Mercury Telluride and Mercury Telluride-Cadmium Telluride," Infrared Physics 2, 53 (1962).

12. M. D. Blue and P. W. Kruse, "Semiconducting Properties of $\operatorname{Hg}_{1-\mathrm{x}} \mathrm{Cd}_{\mathrm{x}} \mathrm{Te}$," Proceedings of the Black Hills Summer Conference on Transport Phenomena, 21-23 August 1962, at the South Dakota School of Mines, Rapid City, South Dakota, pp. 205-218 (1962). DTIC document AD0289290.

http://www.dtic.mil/cgi-bin/GetTRDoc?AD=AD0289290\&Location=U2\&doc=GetTRDoc.pdf

13. R. A. Wood, "Monolithic Silicon Microbolometer Arrays," Chapter 3 in Uncooled Infrared Imaging Arrays and $\underline{\text { Systems, }}$ Volume 47 of Semiconductors and Semimetals, ed. by Paul W. Kruse and David D. Skatrud, pp. 45-122 (Academic Press, New York, 1997). 